\title{
Surface-specific visible light luminescence from composite metal oxide nanocrystals
}

\author{
Andreas Sternig ${ }^{1} \cdot$ Johannes Bernardi $^{2} \cdot$ Keith McKenna $^{3} \cdot$ Oliver Diwald $^{4}$
}

Received: 22 May 2015/Accepted: 27 August 2015/Published online: 8 September 2015

(C) The Author(s) 2015. This article is published with open access at Springerlink.com

\begin{abstract}
Low-coordinated surface elements on metal oxide nanoparticles represent the basis for a new concept of luminescent nanoparticles made of abundant, non-toxic, and thermally stable materials. This combined experimental and theoretical study describes the generation and stability of Ba-doped $\mathrm{MgO}$ nanoparticle surfaces and their optical absorption and luminescence dependence on $\mathrm{Ba}$ loading. It is demonstrated that the vapor phase growth process employed here represents a particularly robust synthesis approach for particle powders with reproducibly adjustable photoluminescence emission properties in the range between blue and yellow light. Moreover, this indepth characterization also provides an understanding of the electronic and optical characteristics of this nanoparticulate material with a so far unnoticed potential for solid-
\end{abstract}

Data relating to the density functional theory calculations performed during this research are available by request from the University of York Research database http://dx.doi.org/10.15124/b04ccc39-95664ed6-8110-f116f86bbf54.

Electronic supplementary material The online version of this article (doi:10.1007/s10853-015-9393-2) contains supplementary material, which is available to authorized users.

Keith McKenna

keith.mckenna@york.ac.uk

$\triangle$ Oliver Diwald

oliver.diwald@sbg.ac.at

Andreas Sternig

sternig.andreas@gmail.com

Johannes Bernardi

bernardi@ustem.tuwien.ac.at

1 Institute of Particle Technology, Friedrich-Alexander

University Erlangen Nürnberg, Cauerstrasse 4,

91058 Erlangen, Germany state light applications that are based on down conversion of UV light.

\section{Introduction}

The quest for luminescent materials of sufficient availability, low price, and biocompatibility is at the heart of nanomaterials research and development with applications in areas such as sensing, lighting, medicine, nanoparticle transport, and the detection of electromagnetic fields [1-6]. Perhaps the most commercially important application of luminescent materials is in solid-state lighting (SSL) devices based on blue and near-UV light-emitting diodes (LEDs) $[1,6]$. While white light can be generated using a combination of separate blue, green, and red light-emitting diodes, in practice much higher efficiencies and better light distribution characteristics are achieved using luminescent materials as downconverters which absorb blue/UV light and emit in the visible spectrum [6]. The importance of this technology as an

2 Vienna University of Technology, University Service Center for TEM (USTEM), Wiedner Hauptstrasse 8-10, 1040 Vienna, Austria

3 Department of Physics, University of York, Heslington, York YO10 5DD, UK

4 Department of Materials Science and Physics, University of Salzburg, Hellbrunner Strasser 34/III, 5020 Salzburg, Austria 
energy-efficient and environment-friendly light source was recognized by the award of the 2014 Nobel Prize in Physics [7]. Improving the efficiency, lifetime, and light-quality of SSL devices while reducing their cost is dependent on developing improved luminescent downconverting materials [1]. Current commercial SSL downconverters use rareearth phosphors such as $\mathrm{Ce}^{3+}$ or $\mathrm{Eu}^{2+}$ embedded in oxide or nitride particles $[3,4]$. To reduce multiple scattering events and improve performance, there has been a drive to reduce particle size. However, this has been found to increase nonradiative recombination at surfaces, reducing quantum yields [2, 8]. Another issue is that rare-earth minerals are extremely dangerous to mine raising human health and ethical issues [7]. For these reasons, there is a great deal of interest in exploring alternative luminescent materials for SSL applications, such as quantum dots (QDs) and inorganic-organic nanocomposites. Such materials should be non-toxic, widely available, safe, and inexpensive to extract and process, thermally and photostable, have high quantum yields, and desirable downconversion characteristics [1]. While luminescent materials satisfying some of these requirements have been demonstrated, there is as yet no material which meets all of them.

In this article, we discuss and explore the potential of nanocrystalline particle systems of pure and composite alkaline earth oxides (AEO) as a new class of downconverting material for SSL applications. AEO have a number of desirable characteristics for SSL applications. They are cheap, widely available, non-toxic, and highly stable. The luminescence in these materials has a surface origin, therefore as particle size is reduced quantum yield is improved, while multiple scattering is minimized [9-12]. AEO can be prepared as highly dispersed solids via gas-phase synthesis and, thus, in the absence of solvents or surface groups that may affect the surface electronic structure in a less controllable way. Consequently, engineering protocols that aim at the reproducible adjustment of color and emission intensity can be developed. In previous work, we have shown how nanocrystalline $\mathrm{MgO}$ exhibits particle-size-dependent absorption and luminescence properties [9] which are connected to low-coordinated sites at the surface such as corners and edges [10-12]. We have also shown how doping with the higher group two metals $\mathrm{Ca}, \mathrm{Sr}$, and $\mathrm{Ba}$ leads to a red-shift in excitation and luminescence energies [13-16]. Here, we present an in-depth investigation of Ba-doped $\mathrm{MgO}$ which has luminescence in the visible range and therefore has potential for SSL applications. By combining first principles theoretical calculations and experimental characterisation, we probe the electronic and optical characteristics of this material with different loadings of $\mathrm{Ba}$. We show that doping $\mathrm{MgO}$ with small concentrations of $\mathrm{Ba}$ leads to a continuous PL emission in the visible range. The effect can be understood in terms of $\mathrm{Ba}$ ions substituting for $\mathrm{Mg}$ ions near low- coordinated features such as corners and edges and thereby modifying associated states participating in electronic transitions. This class of material demonstrates a number of features which make it attractive for applications, for example, in SSL. This detailed study combining different spectroscopic techniques with ab initio calculations provides a firm base for future control over the optoelectronic properties of doped AEO materials.

We first provide a brief overview of the types of inorganic luminescent particles currently in use and development (Fig. 1). The classes of system shown in Fig. 1 differ both in terms of the materials used and the nature of the luminescence effect. Absorption and luminescence in QDs involve transitions between electronic states which are extended throughout the particle volume [17-19]. The luminescence energies can be easily tuned by varying the particle size and shape, and they exhibit a very high quantum yield. On the other hand, QDs are complex nanomaterials to synthesize, often contain toxic elements like $\mathrm{Cd}$, and there are also issues associated with photostability and thermal quenching [1]. Another class of materials system is characterized by dopants (e.g., rare-earth ions) embedded in an inorganic particle which act as luminescence centers (Fig. 1) [3, 4]. In some wide band gap semiconductors, significant luminescence can even be observed in undoped materials due to the presence of intrinsic defects [20-23]. While rare-earthdoped materials are currently employed commercially, there are a number of issues associated with supply, toxicity, and non-radiative surface recombination at surfaces which are problematic [2, 24, 25]. The successful elimination of degradation effects also remains an unresolved topic in many cases. The third class of system shown in Fig. 1 is polymerinorganic composites which are characterized by a chemically more complex and often scarcely characterized interface [5, 26-29]. These materials systems have a variety of advantages which start with the opportunity of self assembly and materials integration into hierarchically organized structures. In particular, hybrid structures comprising biopolymers and functional inorganic phases can replace conventional materials in several high technology or bioapplications that are performed in the ambient or under biocompatible conditions. Many nanocomposites are composed of a luminescent organic dye that is attached to or incorporated in the inorganic nanoparticle [5, 26-29]. Chemical and thermal stability issues as well as materials deterioration via leaching of the luminescence component, however, are continued challenges in the development of this class of material. In the final class of system shown in Fig. 1, the luminescence is associated with low-coordinated surface or interface features on either pure or doped inorganic nanoparticles. For example, highly dispersed AEO surfaces provide bright colored light emission and show a so far unnoticed potential for applications such as inorganic 


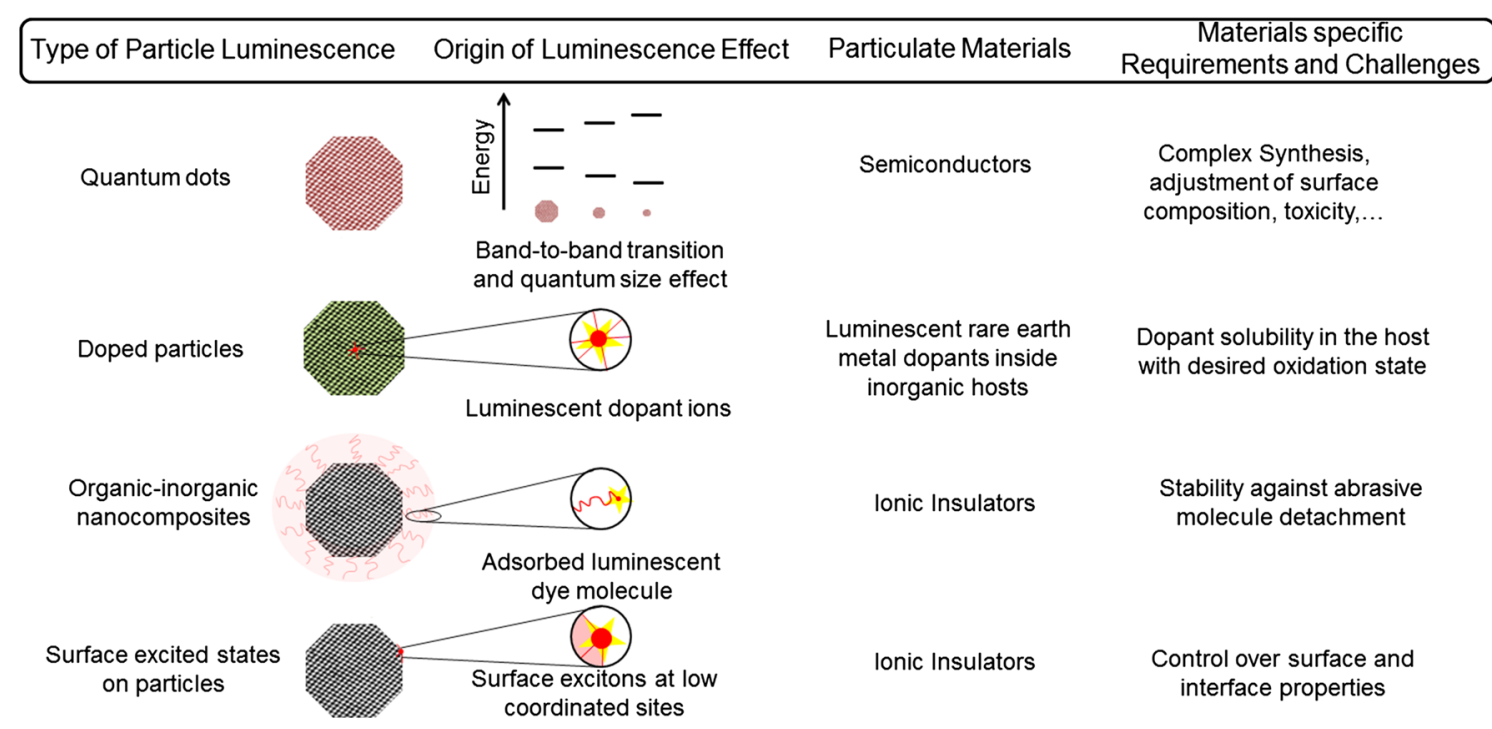

Fig. 1 Schematic illustration of different types of photoluminescent inorganic nanoparticles, nature of the associated photoluminescence emission and related materials challenges

phosphors with adsorption-dependent optical properties [13]. The advantages of this type of material are that it is nontoxic, highly stable, and widely available. In particular, doped AEO nanomaterials are mechanically robust and chemically unreactive and so should not suffer from degradation or stability issues that many of the other classes of system shown in Fig. 1 suffer from (e.g., oxidation of semiconductor dots or abrasive degradation of organicinorganic nanocomposites). Since the luminescence in these materials has a surface origin, scaling particle size to the nanoscale can improve quantum yield while also reducing multiple scattering. On the other hand, tuning and optimizing absorption and luminescence properties of nanoparticles will require precise control over the surface structure and compositon of nanoparticles as well as interfaces between nanoparticles which is challenging [30, 31].

The remainder of the article is organized in the following way. In "Materials and methods" section, we describe the experimental and theoretical methods employed to characterize the structure and properties of Ba-doped MgO nanoparticles. In "Results" section, we present results for the optical absorption and luminescence properties for a range of Ba doping concentrations. Finally, in "Discussion" section, we present a discussion of the results and our conclusions.

\section{Materials and methods}

\section{Materials synthesis}

For the production of $\mathrm{MgO}, \mathrm{Ca}_{\mathrm{x}} \mathrm{Mg}_{1-\mathrm{x}} \mathrm{O}, \mathrm{Sr}_{\mathrm{x}} \mathrm{Mg}_{1-\mathrm{x}} \mathrm{O}$, and $\mathrm{Ba}_{\mathrm{x}} \mathrm{Mg}_{1-\mathrm{x}} \mathrm{O}$ nanoparticles, we used a chemical vapor synthesis (CVS) approach [32] which allows for the controlled combustion of alkaline earth metal vapor under reduced pressures [14, 33, 34]. Stable process conditions are guaranteed by separating evaporation and oxidation zone spatially. For this purpose, the reactor consists of two quartz glass tubes, which are placed inside a cylindrical furnace. The inner tube hosts two ceramic ships with metal pieces each placed in one of the heating zones $\left[\mathrm{T}_{1}(\mathrm{Mg}), \mathrm{T}_{2}\right.$ $(\mathrm{Ca}, \mathrm{Sr}$, or Ba)]. Details of the production of the different types of composites are given elsewhere [13, 33, 35]. A thorough structural analysis of $\mathrm{Ba}_{\mathrm{x}} \mathrm{Mg}_{1-\mathrm{x}} \mathrm{O}$ nanoparticles with integral $\mathrm{Ba}^{2+}$ concentrations of 2,4 or 6 at. $\%$ is provided in Ref. [34].

\section{Materials processing}

After synthesis, the obtained powders are cleaned of organic contaminants by heating to $1123 \mathrm{~K}$ at a rate of $5 \mathrm{~K} \mathrm{~min}^{-1}$ under exposure to molecular oxygen. Thereafter, the sample temperature was raised to $1173 \mathrm{~K}$ at pressures $p<5 \times 10^{-6} \mathrm{mbar}(1 \mathrm{mbar}=100 \mathrm{~Pa})$ and kept at this temperature for $1-2 \mathrm{~h}$. For integral elemental analysis, atomic absorption spectroscopy measurements (PerkinElmer model 2280 using hollow cathode lamps) were performed in such a way that five samples (each $10 \mathrm{mg}$ ) were taken from each preparation charge (typical 300-500 mg powder).

\section{Spectroscopy}

Photoluminescence (PL) and UV diffuse reflectance measurements were carried out at room and liquid nitrogen temperatures using quartz glass cells which guarantee 
vacuum conditions better than $p<10^{-5}$ mbar. The UV diffuse reflectance spectra were acquired in the presence of 10 mbar $\mathrm{O}_{2}$ using a Perkin Elmer Lambda 15 spectrophotometer, equipped with an integrating sphere, and then converted to absorption spectra via the KubelkaMunk transform procedure. A pulsed Xe discharge lamp served as excitation light source in a Perkin Elmer LS 50B system for qualitative PL measurements. Measurements at $T=77 \mathrm{~K}$ were carried out using a commercially available low-temperature luminescence accessory in which the sample was held by a high-purity copper rod that was immersed in liquid nitrogen.

\section{Transmission electron microscopy}

After spectroscopy experiments, small amounts of the metal oxide powders were casted on a holey carbon grid for Transmission Electron Microscopy analysis. The TEM images were obtained using a TECNAI F20 analytical microscope equipped with a S-Twin objective lens and a field emission source operating at $200 \mathrm{kV}$ and were recorded with a Gatan Orius SC600 CCD camera. We carefully checked for potential electron-beam degradation effects of our materials. In fact, we did not observe any significant change of the investigated nanostructures, such as thinning or hole drilling effects or any other types of changes in size and morphology of our composite nanoparticles.

\section{Theoretical methods}

We employ a quantum mechanical embedded cluster method to investigate how $\mathrm{Ba}$ impurities affect the electronic and optical properties of $\mathrm{MgO}$ nanocrystals [16]. In the embedded cluster approach, we divide the nanocrystal into two interacting subregions, which are treated at different levels of theory. A cluster of atoms centered on a particular region of interest (e.g., near a corner of the nanocrystal) is treated at a fully quantum mechanical level, while the remaining atoms are described classically using empirical pair potentials [36]. The total energy of the quantum cluster, in the presence of the electrostatic potential produced by all surrounding classical ions, is obtained by solving the Kohn-Sham equations. The forces acting on all ions are then calculated, and the geometry of the entire system is optimized self-consistently using the BFGS algorithm (e.g., see Refs. [11, 31] for details). The main advantage of this approach is that it allows quantum mechanical treatment of local features in large, complex, and non-periodic nanostructures. Once the nanocrystals are fully optimized, electronic properties can be calculated straightforwardly. Excitation energies are also calculated by time-dependent density functional theory. This type of approach has proved extremely reliable for predicting the electronic, optical, and chemical properties of $\mathrm{MgO}$ nanopowders and a wide range of defects $[11,12,24,30$, 31, 37-39].

In our implementation, $\mathrm{Mg}$ and $\mathrm{O}$ ions in the quantum cluster are described at the all electron level using a Gaussian $6-311 \mathrm{G}^{* *}$ basis set. The core electrons of the heavier $\mathrm{Ba}$ are replaced by a pseudopotential, and a highquality QZVPP basis set is used to describe the valence electrons [25]. The B3LYP hybrid density functional is used for all quantum mechanical calculations with $20 \%$ Hartree-Fock exchange [40]. To test the reliability of the functional and basis set for $\mathrm{Ba}$, we calculated properties of $\mathrm{Ba}$ atoms and $\mathrm{a} \mathrm{BaO}$ molecule. The predicted ionization potentials and equilibrium bond lengths are found to be in very good agreement with experiment (within $3 \%$ ) giving us confidence in this approach. To prevent spurious spilling of the wave function from the quantum cluster into the classically modeled regions, first and second nearest neighbor $\mathrm{Mg}$ are modeled using a semilocal effective core pseudopotential possessing no associated basis functions. Ions in the classical region are described using a polarizable shell model potential [36]. The self-consistent total energy minimization (i.e., quantum and classical regions) is carried out until the change in the total energy is less than $10^{-5} \mathrm{eV}$, and forces on atoms are less than $0.01 \mathrm{eV} \AA^{-1}$. This method is implemented in the GUESS code [11] interfaced with the Gaussian 03 code for the quantum mechanical part of the calculation [42, 43]. Optical excitation energies and oscillator strengths are calculated using the time-dependent density functional theory method as implemented in Gaussian 03 code. The lowest 20 excited states are computed, and the absorption spectrum is simulated using Gaussian broadening with a standard deviation of $0.1 \mathrm{eV}$.

\section{Results}

\section{Modification of optical properties of $\mathrm{MgO}$ nanocrystals by doping}

As described in the Methods section, we synthesize $\mathrm{MgO}$ nanoparticles by controlled combustion of $\mathrm{Mg}$ in a flow reactor followed by subsequent thermal processing. By controlling the parameters of synthesis (such as flow rate and $\mathrm{Mg}$ evaporation rate) and post-processing procedures, it is possible to produce highly cubic and defect-free $\mathrm{MgO}$ nanocrystals with sizes as small as $2 \mathrm{~nm}$. Previous studies have shown how the optical excitation spectra of such nanocrystals, as determined by UV diffuse reflectance spectroscopy, differ significantly from that of bulk crystals. In particular, low-energy electronic transitions are 
observed (in the range 4-6 eV) which are lower in energy than the bulk band gap transition near to $7.7 \mathrm{eV}$ [9-12] (see Fig. 2). These red-shifted absorption features have been attributed to electronic transitions between states localized near low-coordinated surface features, such as terraces, edges, and corners. The fact that the relative intensity of the red-shifted absorption features increases as nanocrystal size is reduced provides convincing experimental evidence for this interpretation [9]. It is further backed up by first principles theoretical calculations of the electronic structure and optical properties of low-coordinated $\mathrm{MgO}$ features.

Composite alkaline-earth nanocrystals consisting of $\mathrm{MgO}$ doped with small concentrations of $\mathrm{Ca}, \mathrm{Sr}$, and $\mathrm{Ba}$ have also been produced by co-combustion $[33,44]$. The effect of doping with heavier alkaline-earth metals on the excitation spectra of nanocrystals is shown in Fig. 2.

Doping induces an overall red-shift of the absorption spectra. As for pure $\mathrm{MgO}$ nanocrystals, the lowest energy excitations are far below the bulk band gap transition energies of the corresponding pure oxides $(6.8,5.8$, and $4.1 \mathrm{eV}$ for $\mathrm{CaO}, \mathrm{SrO}$, and $\mathrm{BaO}$ respectively). Therefore, these absorption features are attributed to low-coordinated structural features which are modified by the presence of dopant ions. In particular, the presence of $\mathrm{Ca}, \mathrm{Sr}$, and $\mathrm{Ba}$ near low-coordinated corner features modifies associated electronic states which are localized there and correspondingly leads to a red-shift in the excitation energies. Importantly, Ba-doped $\mathrm{MgO}$ nanocrystals exhibit optical

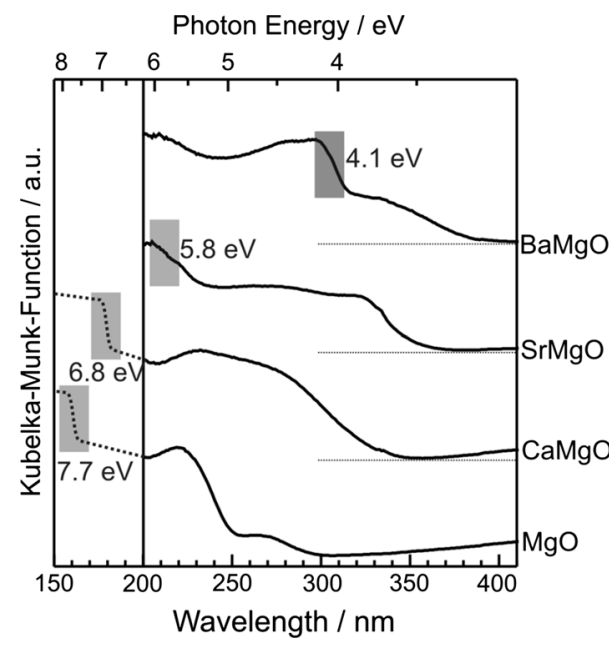

Fig. 2 UV diffuse reflectance spectra of vacuum-annealed $\mathrm{MgO}$, $\mathrm{CaMgO}\left(10\right.$ at $\left.\% \mathrm{Ca}^{2+}\right), \operatorname{SrMgO}\left(12\right.$ at $\left.\% \mathrm{Sr}^{2+}\right)$, and $\mathrm{BaMgO}(6$ at $\%$ $\left.\mathrm{Ba}^{2+}\right)$ particles. The wavelength range above $200 \mathrm{~nm}$ is experimentally accessible. Values below $200 \mathrm{~nm}$ illustrate the expected absorption trends. The gray squares depict the energy range where band gap transitions are expected for pure alkaline earth oxides. Spectra are shifted on the abscissa for clarity. The dashed lines correspond to the baseline of the individual spectra absorption in the near-UV region and luminescence in the visible region which may be of interest for practical applications. Such ionic nanocrystal systems represent a novel class of luminescent material due to the intrinsic surface nature of both the absorption and luminescence process (see Fig. 1).

\section{Ba doping of MgO nanocrystals}

We now focus on the BaO-doped $\mathrm{MgO}$ composite nanocrystals and consider the effect of $\mathrm{Ba}$ concentration by examining samples with nominal molar $\mathrm{BaO}$ concentrations of 2,4 , and $6 \%$. The structure of each of these powder samples is characterized by both transmission electron microscopy (TEM) and X-ray diffraction (XRD) (Fig. 3a-c). A Ba concentration of $6.0 \pm 1.5 \%$ was determined for the $\mathrm{Ba}_{0.06} \mathrm{Mg}_{0.94} \mathrm{O}$ samples, which were found to be more inhomogeneous and show phase separation which leads to $\mathrm{BaO}$ clusters separating to the surface of the MgO-based $\mathrm{Ba}_{x} \mathrm{Mg}_{1-x} \mathrm{O}$ nanoparticles. A detailed discussion of related high-resolution (HR) TEM data and results from energy filtering transmission electron microscopy (EFTEM) is provided in Ref. [34] and further examples are shown in the Supporting Information. In case of samples with $\mathrm{Ba}$ contents $x \leq 0.04$, the admixture of $\mathrm{Ba}^{2+}$ ions leads to a slight average particle size increase from $d_{\mathrm{TEM}}=6 \mathrm{~nm} \quad(\mathrm{MgO})$ to $d_{\mathrm{TEM}}=7 \mathrm{~nm} \quad\left(\mathrm{Ba}_{0.02-}\right.$ $\left.\mathrm{Mg}_{0.98} \mathrm{O}\right)$ and $d_{\text {TEM }}=8 \mathrm{~nm}\left(\mathrm{Ba}_{0.04} \mathrm{Mg}_{0.96} \mathrm{O}\right)$ (Fig. $3 \mathrm{~d}$, Ref. [34]). In addition, we also realized a slight loss of the high morphological definition that is specific to $\mathrm{MgO}$ nanocubes. However, in none of these samples, we were able to identify phase separation effects with HR-TEM, EFTEM, and XRD [34].

While TEM and XRD can provide invaluable information on the effect of Ba dopants on the morphology of the $\mathrm{MgO}$ powders, it is more challenging to probe their atomic scale structure. To provide insight into this important issue, we employ first principles theoretical calculations.

To characterize the relative stability of substitutional $\mathrm{Ba}$ impurities in $\mathrm{MgO}$ nanocrystals, we perform quantum mechanical embedded cluster calculations as described in detail in the Methods section. We consider quantum clusters centered at positions in the bulk of a $\mathrm{MgO}$ nanoparticle, at the (001) terrace, at the edge, and near anion and cation-terminated corners. For each quantum cluster, we determine the atomic structure and total energy associated with individual $\mathrm{Ba}$ ions substituting $\mathrm{Mg}$ ions of different coordination. Figure 4 shows the optimized structure of all inequivalent $\mathrm{Ba}$ sites within these clusters. At the cationterminated corner, we consider substitution of the threecoordinated (3C) and $5 \mathrm{C} \mathrm{Mg}$ with $\mathrm{Ba}$, at the anion-terminated corner and edge, we consider substitution of the $4 \mathrm{C}$ $\mathrm{Mg}$ with $\mathrm{Ba}$, and at the (001) terrace, we consider 
Fig. 3 Transmission electron microscopy images of $\mathrm{MgO}$ powders doped with 2 (a), 4 (b), and $6 \%(\mathbf{c})$ of $\mathrm{Ba}$. The related particle size distributions are plotted in (d)
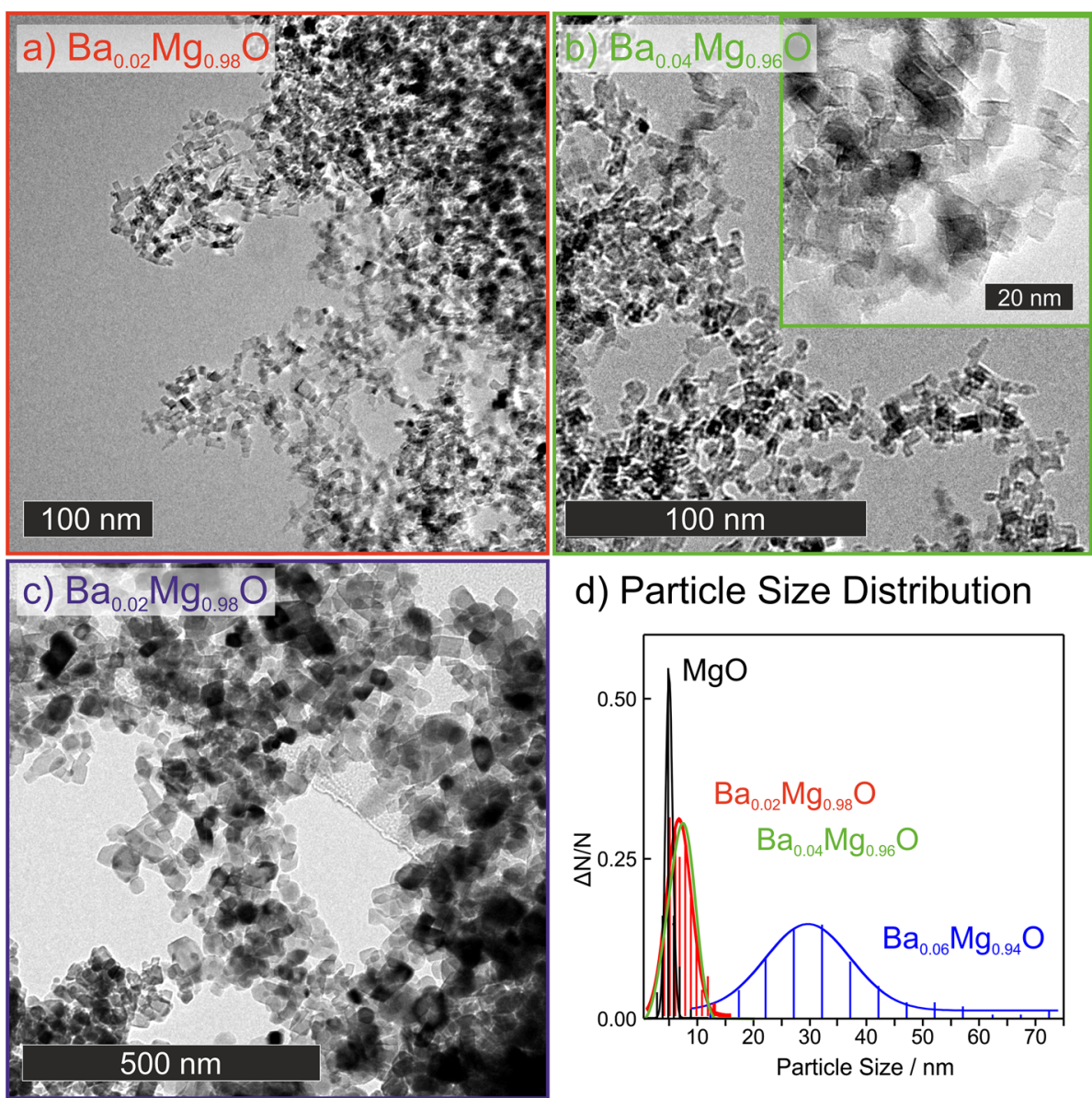

d) Particle Size Distribution

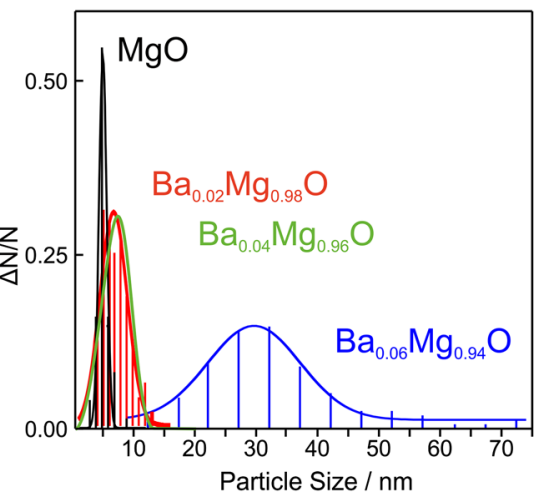

substitution of the $5 \mathrm{C} \mathrm{Mg}$ with $\mathrm{Ba}$. We calculate incorporation energies, $E_{\text {inc }}$, for each of these substitutional sites as defined by the following reaction.

$\mathrm{Ba}+\mathrm{Mg}_{n} \mathrm{O}_{n}+E_{\text {inc }} \rightarrow \mathrm{BaMg}_{n-1} \mathrm{O}_{n}+\mathrm{Mg}$

which represents the change in energy associated with exchanging a gas-phase $\mathrm{Ba}$ atom for a $\mathrm{Mg}$ atom embedded in $\mathrm{MgO}$. Table 1 summarizes the calculated incorporation energies for all of the surface sites shown in Fig. 4 as well as for substitution of a bulk (6C) $\mathrm{Mg}$ ion.

We find that incorporation of $\mathrm{Ba}$ into bulk $\mathrm{MgO}$ is extremely unfavorable. This is because of the significant lattice strain introduced by substituting the larger $\mathrm{Ba}^{2+}$ ion with the smaller $\mathrm{Mg}^{2+}$ ion. This is also reflected in the lattice constant of rocksalt-structured $\mathrm{BaO}$ which is about $30 \%$ larger than that of $\mathrm{MgO}$. Similar calculations performed for incorporation of the smaller isovalent ions $\mathrm{Sr}^{2+}$ and $\mathrm{Ca}^{2+}$ into bulk $\mathrm{MgO}$ predict much smaller incorporation energies $(+3.72$ and $+0.83 \mathrm{eV}$, respectively) illustrating this effect. However, incorporation of $\mathrm{Ba}$ into surface sites (corner and edge) is much more favorable owing to the greater freedom for relaxation which can accommodate the ion mismatch. The outwards relaxation of surface $\mathrm{Ba}$ ions is apparent in the optimized structure of the quantum clusters shown in Fig. 4. In highly non-equilibrium growth processes, which are characteristic of growth by CVS, Ba may be incorporated into both bulk and surface sites. However, we predict that given sufficient time and thermal energy preferential segregation of Ba to surface sites are most likely. In the 2 and $4 \%$ samples which do not show significant phase separation, we expect such surface-doped sites to be common.

\section{Optical excitation properties}

We now turn to address the optical excitation properties of Ba-doped $\mathrm{MgO}$ powders. Figure 5 shows UV diffuse reflectance spectra of vacuum-annealed and dehydroxylated $\mathrm{MgO}$ - and $\mathrm{Ba}$-doped $\mathrm{MgO}$ powders with $0,2,4$, and $6 \% \mathrm{BaO}$ concentration. Adding $2 \% \mathrm{BaO}$ leads to a dramatic red-shift of the absorption onset compared to pure $\mathrm{MgO}$. In pure $\mathrm{MgO}$, the absorption onset is close to $4.0 \mathrm{eV}$ with a small low-energy peak near $4.7 \mathrm{eV}$ which has 
Fig. 4 The optimized structure of various Ba-substituted surface features in $\mathrm{MgO}$ nanoparticles. Oxygen ions (large red balls), magnesium ions (small green balls), and barium ions (large orange balls) (Color figure online)

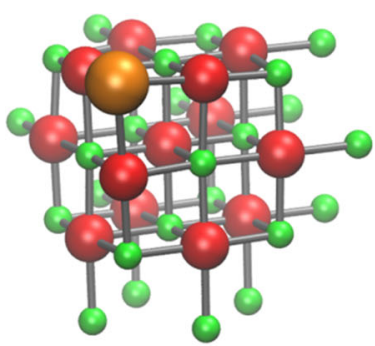

Cation corner - 3C

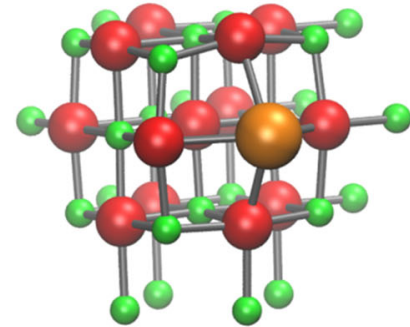

Cation corner $-5 \mathrm{C}$

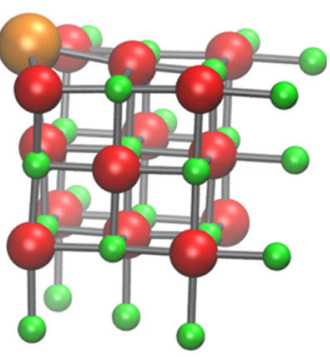

Anion corner - 4C

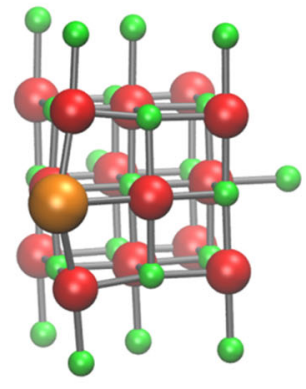

Edge - 4C

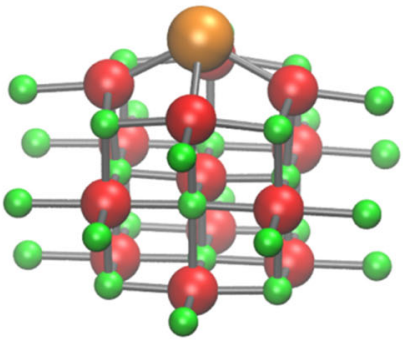

Terrace $-5 \mathrm{C}$
Table 1 Calculated incorporation energies associated with exchanging $\mathrm{Mg}$ for $\mathrm{Ba}$ at various structural features in $\mathrm{MgO}$ nanocrystals [as defined by Eq. (1)]

\begin{tabular}{lll}
\hline Nanocrystal feature & Site coordination & Incorporation energy $(\mathrm{eV})$ \\
\hline Cation corner & 3 & -1.51 \\
Anion corner & 4 & -1.00 \\
Edge & 4 & -1.14 \\
Cation corner & 5 & +0.28 \\
$(100)$ terrace & 5 & +0.39 \\
Bulk & 6 & +7.27 \\
\hline
\end{tabular}

previously been attributed to transitions between electronic states localized near corner features [9-12]. On introduction of $\mathrm{Ba}$, the absorption onset is reduced by about $0.5 \mathrm{eV}$ and the low-energy peak near $4.7 \mathrm{eV}$ is no longer clearly discernable. Increasing of the Ba loading to 4 and $6 \%$ results in the gradual development of an absorption edge corresponding to band gap transitions of pure $\mathrm{BaO}$ (gray squares in Fig. 5) which we attribute to phase-separated clusters supported on the $\mathrm{MgO}$ nanoparticles [14]. However, the lower energy excitations related to Ba-substituted $\mathrm{MgO}$ surface features remain relatively unchanged. Further evidence that these low-energy excitations are connected to $\mathrm{MgO}$ surface features with $\mathrm{Ba}$ substituting some of the $\mathrm{Mg}$ ions is given by PL excitation spectroscopy which we discuss in detail later in the manuscript (Fig. 9).

To provide insight into the nature of the modified excitations introduced by $\mathrm{Ba}$ doping, we perform timedependent density functional calculations on Ba-doped

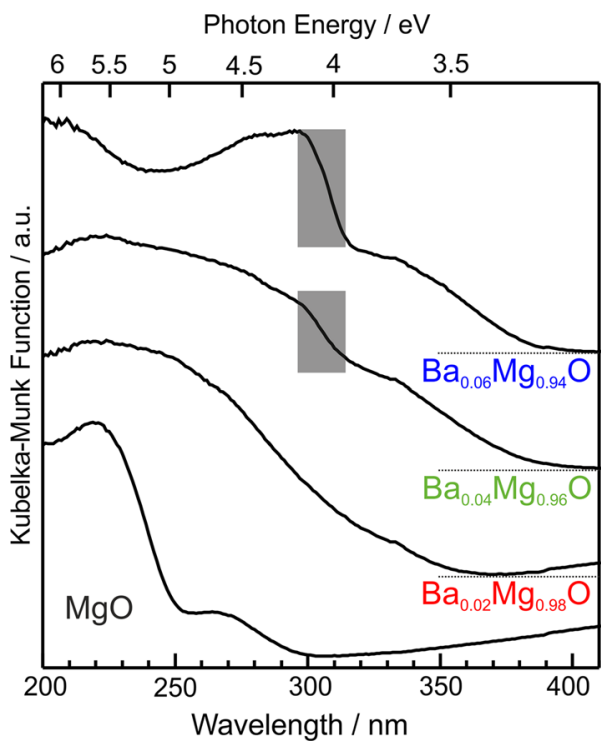

Fig. 5 UV diffuse reflectance spectra of Ba-doped $\mathrm{MgO}$ powders. Spectra are shifted on the abscissa for clarity. The dashed lines correspond to the baseline of the individual spectra

surface features to predict corresponding excitation spectra. We focus on the modification of the absorption of corner features since these are known to be responsible for the low-energy excitations in pure $\mathrm{MgO}$ and are also the most favorable sites for $\mathrm{Ba}$ incorporation owing to the increased freedom for relaxation and accommodation of the larger $\mathrm{Ba}$ ions. Figure 6a shows the calculated excitation spectrum of an anion-terminated corner in a $\mathrm{MgO}$ nanocrystal and the corresponding spectrum when a four-coordinated (4C) $\mathrm{Mg}$ ion adjacent to the corner is substituted for a $\mathrm{Ba}$ ion. The 
overall shape of the spectrum is very similar in both cases, but substitution of Ba leads to a red-shift of the excitation energies by about $0.4 \mathrm{eV}$. Analysis of the nature of electronic transitions shows that in both cases they involve excitation of an electron from a state involving $\mathrm{O} 2 p$ orbitals localized near the corner to a state primarily localized on the $\mathrm{Ba}$ ion. Figure $6 \mathrm{~b}$ shows the effect of $\mathrm{Ba}$ substitution near a cation-terminated corner. For $\mathrm{Ba}$ at the $3 \mathrm{C}$ site, the spectrum is red-shifted by about $0.3 \mathrm{eV}$ with little change in shape. For $\mathrm{Ba}$ at the $5 \mathrm{C}$ site, there is a significant change in the shape of the spectrum and introduction of low-energy excitations. Ba substituting at edge and terrace features introduces similarly low excitations in the range $4-5 \mathrm{eV}$. In all cases, the red-shifted excitations result from the introduction of lower unoccupied electronic states on the $\mathrm{Ba}$ ion and modification of occupied $\mathrm{O}$ $2 p$ states by $\mathrm{Ba}$.

The general observation that $\mathrm{Ba}$ substitution reduces the excitation energies of $\mathrm{MgO}$ surface features can be understood in terms of the Ba-induced perturbation of electronic states. The calculated vertical ionization energy of $\mathrm{Ba}$ containing features is reduced by typically $0.1-0.2 \mathrm{eV}$ compared to the corresponding pure $\mathrm{MgO}$ feature. In other words, holes are bound slightly more strongly to features containing $\mathrm{Ba}$. Analogously, in most cases, Ba containing features possess a slightly increased electron affinity (the only exception being the $3 \mathrm{C}$ cation terminated corner which possesses a large electron affinity even without $\mathrm{Ba}$ ). Therefore, the reduced excitation energies are a result of both an increase in the energy of the highest occupied molecular orbitals and a decrease in the

(a)

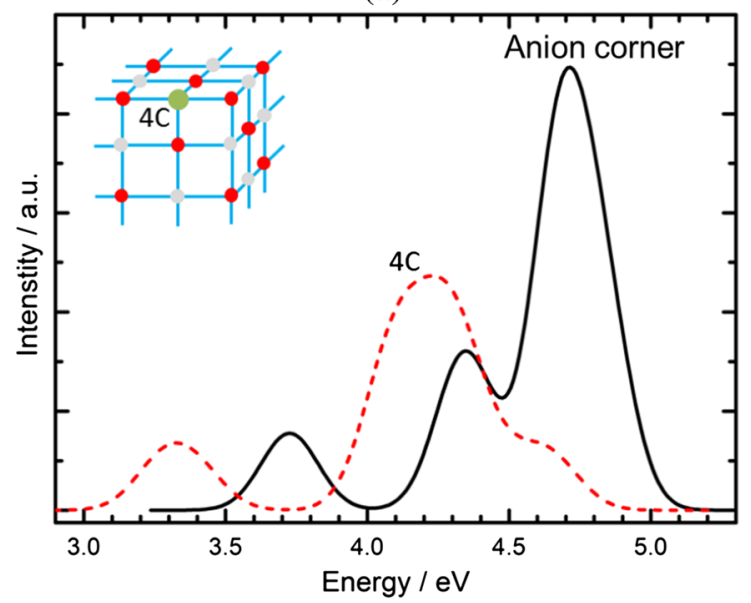

Fig. 6 a Calculated optical excitation spectra of an anion-terminated corner feature in a pure $\mathrm{MgO}$ nanocrystal (black solid line) and the corresponding spectra on substitution of a $4 \mathrm{C}$ cation near the anion corner with a $\mathrm{Ba}$ ion (red dashed line). The inset shows schematically the position of the $\mathrm{Ba}$ ion. $\mathbf{b}$ Calculated optical excitation spectra of a cation-terminated corner feature in a pure $\mathrm{MgO}$ nanocrystal (black energy of the lowest unoccupied molecular orbitals. To illustrate the effect of Ba impurities on optical absorption, the calculated spectra of individual features can be combined to simulate the absorption spectrum of $\mathrm{MgO}$ powders. Figure 7 shows the simulated spectrum obtained by summing the contributions due to pure $\mathrm{MgO}$ corner, edge, and terrace features in proportions appropriate for a $2 \mathrm{~nm}$ cubic nanocrystals. As shown previously, this simulation accurately reproduces the experimental absorption spectra of loose $\mathrm{MgO}$ powders. Figure 7 also shows how the absorption is modified if $\mathrm{Ba}$ impurities are incorporated at the most stable corner features. The main effect of $\mathrm{Ba}$ is to red-shift the peak in absorption due to corners from about $4.7 \mathrm{eV}$ (red dashed line in Fig. 6) to about $4.2 \mathrm{eV}$ (orange solid line in Fig. 7). Incorporation of $\mathrm{Ba}$ also reduces the lowest energy absorption, albeit very low intensity, from 3.7 to $3.1 \mathrm{eV}$.

\section{Photoluminescence properties}

To assess the PL properties of Ba-doped $\mathrm{MgO}$ powders, we measure PL spectra under monochromatic irradiation at $\lambda_{\mathrm{EXC}}=340 \mathrm{~nm}(3.6 \mathrm{eV})$ and $\lambda_{\mathrm{EXC}}=390 \mathrm{~nm}(3.2 \mathrm{eV})$. These excitation energies are chosen to correspond exclusively to surface exciton formation at low-coordinated Barelated surface features (see Fig. 4). Figure 8 summarizes the PL spectra for the 2, 4, and $6 \%$ samples both at room temperature $(298 \mathrm{~K})$ and at liquid nitrogen temperature $(77 \mathrm{~K})$. For all samples using $\lambda_{\mathrm{EXC}}=390 \mathrm{~nm}(3.2 \mathrm{eV})$, we find efficient and temperature-dependent PL with emission bands peaked near 2.3 and $2.6 \mathrm{eV}$ for 77 and $298 \mathrm{~K}$, (b)

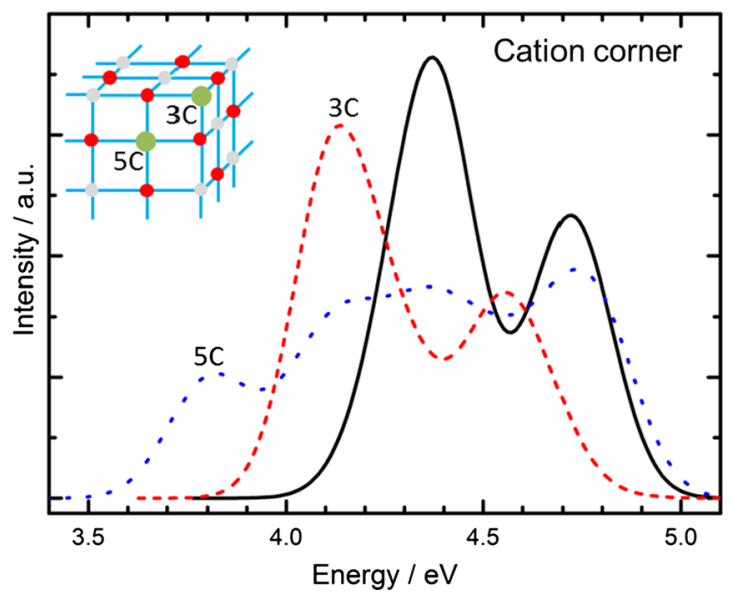

solid line) and the corresponding spectra on substitution of a $3 \mathrm{C}$ cation and a $5 \mathrm{C}$ cation near the corner with a $\mathrm{Ba}$ ion (red and blue dashed lines, respectively). The inset shows schematically the positions of the Ba ions. Refer to Fig. 4 for a more detailed depiction of the local structure (Color figure online) 


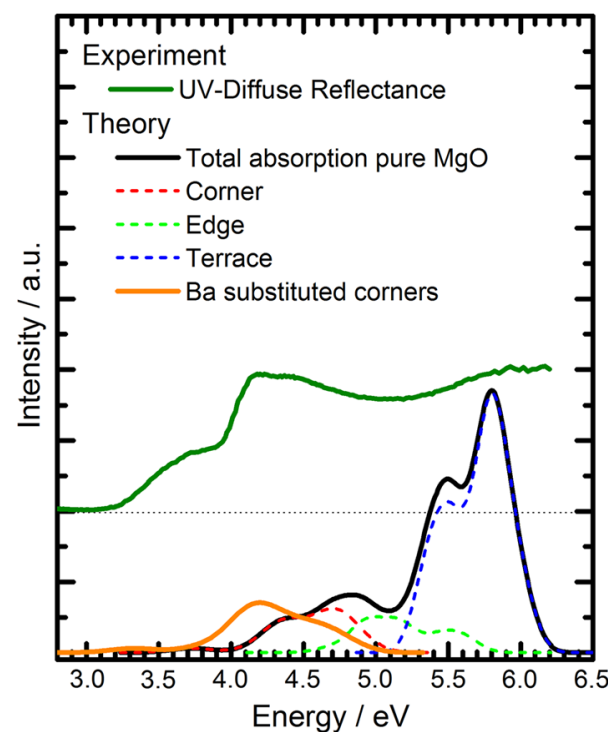

Fig. 7 Theoretically predicted absorption spectra for pure $\mathrm{MgO}$ nanocrystals of approximate size $2 \mathrm{~nm}$. The overlapping contributions due to corner, edge, and terrace features are also shown (dashed lines). Substitution of $\mathrm{Ba}$ for $\mathrm{Mg}$ at corner features gives rise to absorption at lower energies, with a red-shifted peak in absorption due to corners at $4.2 \mathrm{eV}$. For comparison, the green curve shows and experimentally acquired diffuse reflectance spectrum of a $\mathrm{Ba}_{0.06}$ $\mathrm{Mg}_{0.94} \mathrm{O}$ nanoparticle powder (see also bottom curve Fig. 5)

respectively. Using $\lambda_{\mathrm{EXC}}=340 \mathrm{~nm}(3.6 \mathrm{eV})$, we find the peak in the emission bands moves to $2.7 \mathrm{eV}$ independent of temperature. An important characteristic related to the PL emission properties of $\mathrm{BaO}$-doped $\mathrm{MgO}$ nanocrystals is that in terms of band position and structure, they are essentially the same for all $\mathrm{BaO}$ loadings investigated. We note that these emission bands are quenched perfectly on exposure to gaseous oxygen confirming that the entire luminescence process (excitation and emission) is connected with $\mathrm{Ba}^{2+}$ ions that have efficiently segregated to the $\mathrm{MgO}$ particle surface. This is also consistent with the theoretical predictions presented in the previous sections. The associated PL quantum yields are above $10 \%$ and can be increased by a factor $2-3$ when the temperature is reduced to $T=77 \mathrm{~K}$. The cooling-induced gain in intensity partly originates from a broad feature centered at $\lambda=555 \mathrm{~nm}$ (gray curves in Fig. 8), which can be photogenerated with excitation at $\lambda_{\mathrm{EXC}}=340 \mathrm{~nm}$ as well as at $\lambda_{\text {EXC }}=390 \mathrm{~nm}$. Qualitatively different emission bands result from photoexcitation at these two wavelengths at room temperature. Such phenomena are attributed to energy transfer processes across the surface of $\mathrm{BaO}$-doped $\mathrm{MgO}$ particles and differences in the kinetics of radiative and non-radiative decay processes.

To obtain more detailed information on the correlation between excitation and PL emission, we measure the PL excitation spectrum. For the $6 \%$ sample, we examine the

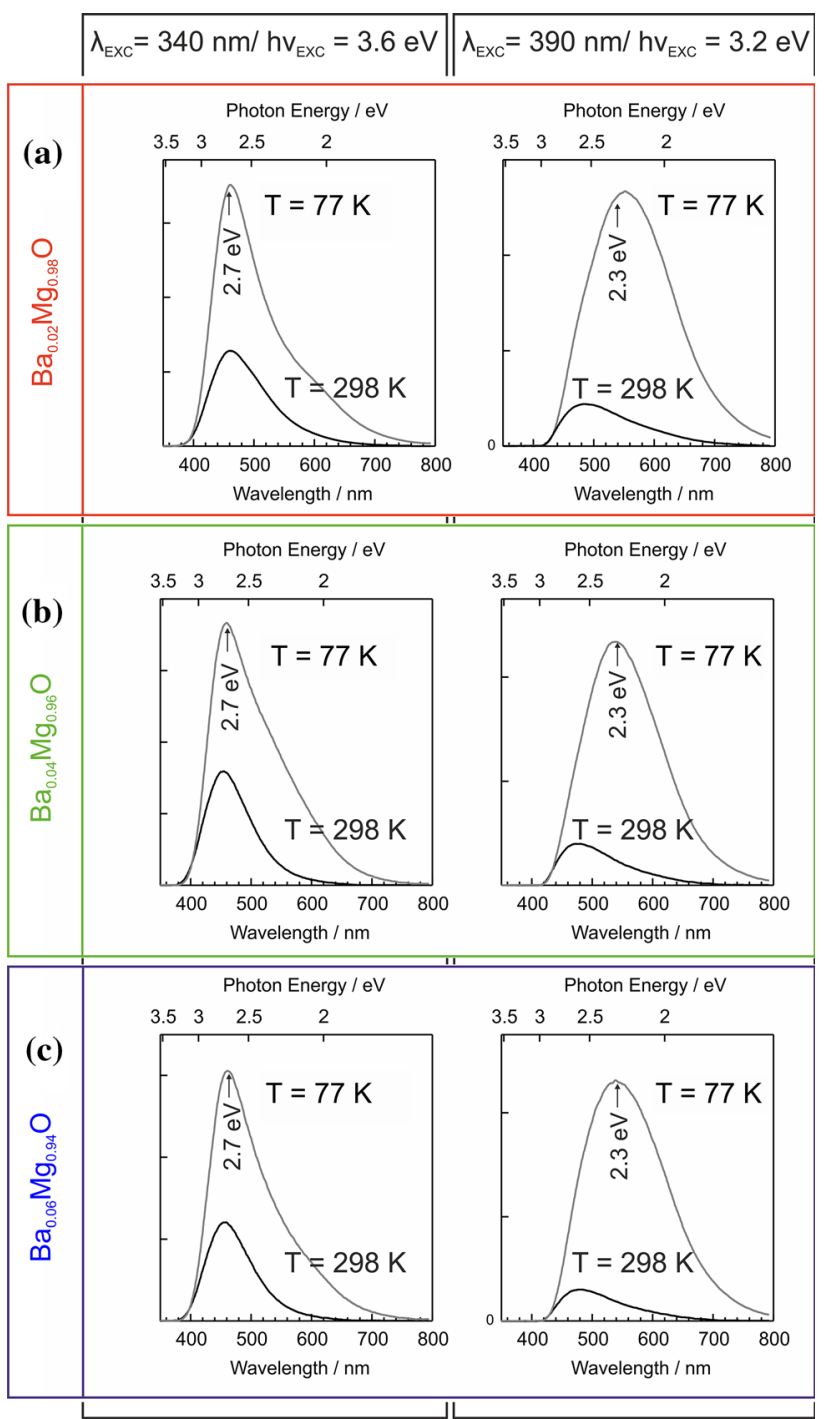

Fig. 8 Photoluminescence of Ba-doped $\mathrm{MgO}$ particles for $2 \%$ (top row), $4 \%$ (middle row), and $6 \%$ (bottom row) $\mathrm{BaO}$ loadings. PL spectra are shown for two different monochromatic excitation energies, $\lambda_{\mathrm{EXC}}=340 \mathrm{~nm}(3.6 \mathrm{eV})$ and $\lambda_{\mathrm{EXC}}=390 \mathrm{~nm}(3.2 \mathrm{eV})$, at both room temperature $(298 \mathrm{~K})$ and liquid nitrogen temperature $(77 \mathrm{~K})$

major excitations responsible for the visible light emission at $\lambda_{\mathrm{EM}}=580 \mathrm{~nm}\left(h v_{\mathrm{EM}}=2.1 \mathrm{eV}\right)$ corresponding to visible light emission. Figure 9 shows the PL excitation spectrum together with the UV diffuse reflectance spectra for the same sample. There are three distinct excitation maxima at $320 \mathrm{~nm}(3.9 \mathrm{eV}), 345 \mathrm{~nm}(3.6 \mathrm{eV})$, and $390 \mathrm{~nm}$ $(3.2 \mathrm{eV})$ which contribute to the PL emission at $580 \mathrm{~nm}$. Examining the corresponding UV diffuse reflectance spectrum in Fig. 9, these energies fall in the region below the strong absorption feature at $4.1 \mathrm{eV}$ which is identified as a bulk band gap transitions in pure $\mathrm{BaO}$. Therefore, we tentatively assign these excitations to transitions between electronic states localized near low-coordinated Ba-doped 
features, such as corners and edges (e.g., 3C, 4C and 5C sites). The truncation of the excitation spectrum at energies above $h v_{\text {EXC }}=4.1 \mathrm{eV}$ (Fig. 9b) is interesting to note and can have different reasons or a combination thereof: (i) luminescence emission which originates from the excitation of $\mathrm{BaO}$ clusters in the bulk is substantially weaker than that related to the photoexcitation of low-coordinated Ba-doped (and MgO-based) surface features; (ii) the concentration of $\mathrm{BaO}$ clusters in the sampled powder volume is too small in order to significantly contribute to the overall emission at $\lambda_{\mathrm{EM}}=580 \mathrm{~nm}\left(h v_{\mathrm{EM}}=2.1 \mathrm{eV}\right)$ or (iii) inefficient energy transfer across the solid-solid interface between the $\mathrm{BaMgO}$ particle and the supported $\mathrm{BaO}$ cluster [34].

Theoretical calculation of PL spectra in complex nanostructures is extremely challenging since it requires reliable and accurate methods to describe the time evolution and diffusion of excited electronic states, including coupling to lattice vibrations. However, an indication of trends in PL energies can be obtained by considering transitions between a triplet exciton localized at a particular feature in the nanocrystal and the singlet ground state. For example, to consider the modification of PL at the anion-terminated corner on incorporation of $\mathrm{Ba}$, we first find the relaxed atomic configuration for the triplet exciton starting with the atomic structure obtained previously (see Fig. 4). We then calculate the vertical singlet-triplet energy difference $\left(\Delta_{\mathrm{ST}}\right)$ with atomic coordinated frozen. For the pure $\mathrm{MgO}$ anion corner, we find $\Delta_{\mathrm{ST}}=2.6 \mathrm{eV}$, whereas on substitution of a $4 \mathrm{C} \mathrm{Mg}$ ion adjacent to the corner with $\mathrm{Ba}$, we find $\Delta_{\mathrm{ST}}=1.6 \mathrm{eV}$. Therefore, these calculations predict that PL energies for excitons near

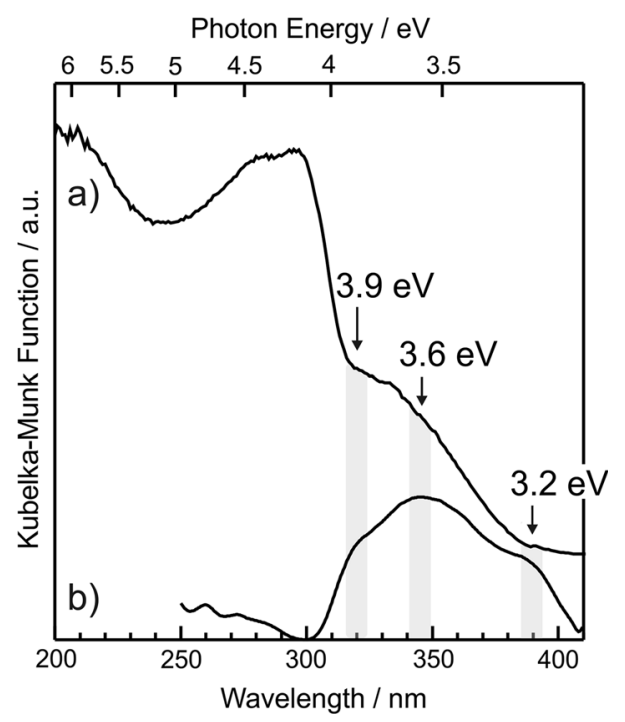

Fig. 9 a UV diffuse reflectance and $\mathbf{b}$ photoluminescence excitation spectra $\left(\lambda_{\mathrm{EM}}=580 \mathrm{~nm}, h v_{\mathrm{EM}}=2.1 \mathrm{eV}\right)$ for the $6 \% \mathrm{BaO}$-doped $\mathrm{MgO}$ powder sample anion corners should be red-shifted by about $1 \mathrm{eV}$ by introduction of Ba impurities. For comparison, room temperature $\mathrm{PL}$ emission is peaked near $3.2 \mathrm{eV}$ in pure $\mathrm{MgO}$ nanocrystals and is reduced to $2.6 \mathrm{eV}$ on $\mathrm{Ba}$ doping, corresponding to a red-shift $0.6 \mathrm{eV}$.

For lighting applications, it is important to be able to precisely control the color of the emission. The required balance of the emission spectrum across a broad band of energies seems feasible by using $\mathrm{BaO}$-doped metal oxide nanoparticles. We analyzed the color characteristics of light emitted following UV excitation of Ba-doped $\mathrm{MgO}$. Figure 10 shows the International Commission on Illumination (CIE) chromaticity chart where the color of the emission from the $6 \% \mathrm{BaO}$ sample is plotted for two different excitation energies and temperatures. Already for the two selected excitation wavelengths $\lambda_{\mathrm{EXC}}=340$ and $390 \mathrm{~nm}$, it can be shown that the emission color is tunable from the blue to the yellow region of the visible spectrum. This example clearly demonstrates that changing the excitation wavelength - or even more effective-changing the spectrum of the excitation source in conjunction with the temperature allows for significant and adjustable color changes.

\section{Discussion}

Through a combination of HR-TEM, EFTEM, and XRD, we can conclude that for Ba contents less than or equal to $4 \%$, there is no significant phase separation suggesting $\mathrm{Ba}$ ions are incorporated substitutionally in the $\mathrm{MgO}$ lattice [34]. Accompanied with the introduction of $\mathrm{Ba}$ is a slight increase in the average particle size and a slight loss of the highly cubic nanocrystal morphology. Owing to the larger ionic radii $\mathrm{Ba}$ is expected to preferentially occupy sites of reduced coordination at surfaces. This expectation is supported by the first principles theoretical calculations showing $\mathrm{Ba}$ ions at surfaces are around $8 \mathrm{eV}$ more stable than in the bulk. The structural models of the surface $\mathrm{Ba}$ sites are relatively simple-involving substitution of $\mathrm{Mg}$ for $\mathrm{Ba}$ at highly symmetrical structural features such a nanocube corners and edges. Here, we do not consider the possibility that $\mathrm{Ba}$ segregation may induce a reconstruction of surface features, nor do we consider more complex features such as interfaces [30, 31]. A more complete model would need to consider a statistically representative distribution of complex Ba-modified surface/interfaces features. The simpler models considered here offer a compromise between simplicity and feasibility allowing us to investigate the effects of $\mathrm{Ba}$ doping on the optical properties of $\mathrm{MgO}$ nanocrystals in a systematic way.

The UV diffuse reflectance spectra measurements show that doping with small amounts of $\mathrm{Ba}$ induces significant 


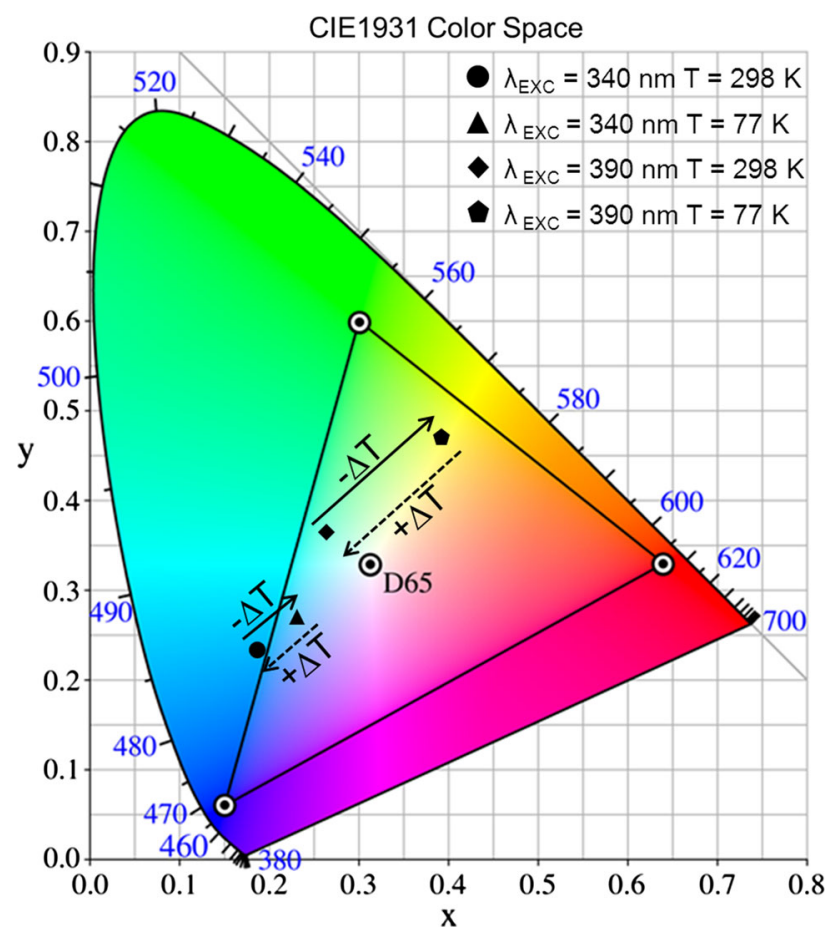

Fig. 10 CIE1931 color space with marked coordinates, which represent the color of the emission spectra recorded for $\mathrm{Ba}_{0.06} \mathrm{Mg}_{0.94} \mathrm{O}$ particles using $\lambda_{\mathrm{EXC}}=340 \mathrm{~nm}(3.6 \mathrm{eV})$ and $\lambda_{\mathrm{EXC}}=390 \mathrm{~nm}$ $(3.2 \mathrm{eV})$ at $T=298$ and $T=77 \mathrm{~K}$. The point indicated as D65 corresponds to the solar standard

changes in the optical absorption spectra of $\mathrm{MgO}$ nanocrystals. In particular, absorption features are introduced at lower energies than that observed for pure $\mathrm{MgO}$. The theoretical calculations of optical absorption spectra help to explain this effect as resulting from electronic transitions involving $\mathrm{Ba}$ ions located at low-coordinated surface sites. The excited state calculations are performed using time-dependent density functional theory and the B3LYP hybrid density functional theory which has been shown to predict optical excitation energies in $\mathrm{MgO}$ for a wide range of defects, in good agreement with experiment $[30,41]$. These calculations show that incorporation of $\mathrm{Ba}$ leads to a red-shift in the optical absorption in semiquantitative agrement with the experimental results. A full quantitative prediction of the absorption spectra would require a more complete sampling of the possible local environments of $\mathrm{Ba}$ in the $\mathrm{MgO}$ nanopowders.

\section{Conclusions}

The results presented in this article demonstrate that by doping $\mathrm{MgO}$ with small concentrations of $\mathrm{Ba}$, it is possible to modify surface-related excitation and luminescence spectra. This effect can be understood in terms of $\mathrm{Ba}$ ions substituting for $\mathrm{Mg}$ ions near low-coordinated features such as corners and edges and thereby modifying associated states participating in electronic transitions. In particular, we have shown how doping with Ba leads to a red-shift in both absorption and PL spectra. We note that the continuous PL emission in the visible range that the Ba-doped $\mathrm{MgO}$ powders exhibit is a desirable characteristic of a SSL downconverting material as it permits white light to be generated using only a single phosphor. Importantly, $\mathrm{BaO}$ surface deposits which are observed to emerge above a critical $\mathrm{BaO}$ concentration as a consequence of segregation and dewetting do not further influence the PL properties in this optical range. This observation makes controlled cocombustion of $\mathrm{Ba}$ and $\mathrm{Mg}$ vapors an even more robust synthesis approach, because it shows that $\mathrm{BaO}$ amounts that exceed the range of surface doping do not exert any type of detrimental effect to the PL properties.

The doped $\mathrm{MgO}$ powders are shown to exhibit temperature-dependent PL spectra which may be a promising feature for applications. For example, the controlled activation of energy transfer provides a means to tune the shades of white light emission for SSL devices. It could also be used as a probe of the local temperature in thermally non-conducting media by tracking the spectral position and integral intensity of the appropriate emission feature.

While the particular color and temperature dependence exhibited by the samples considered here are not optimal for SSL applications, there are indications that properties could be further improved by controlling particle morphology, doping levels, and post-processing treatments. In addition, practical SSL downconverters should have quantum yields close to $95 \%$. Owing to the surface/interface nature of PL emission in these materials, improved quantum yields can be obtained simply by increasing the concentration of active low-coordinated sites. This can be achieved by reducing particle size, modifying surface structure, or compression of nanopowders. In a recent work, we have demonstrated that extended defects such as grain boundaries and dislocations introduced by compression introduce absorption and PL emission features with even lower energies than low-coordinated surface sites [24, 31]. Early studies suggest quantum yields can be increased easily to above $25 \%$ and this is without systematic optimization.

We have shown that combining detailed materials characterization with theoretical modeling is a very powerful approach for understanding the effect of dopants on optical properties of oxide particles. In a similar way, in previous work, we have addressed the specific properties of interfaces. Such theoretical models could provide a useful guide to identify suitable dopants and strategies to optimize PL characteristics for SSL applications. One of the major 
challenges is accurate theoretical prediction of PL spectra for such systems which necessitate modeling the time evolution of excited electronic states, transfer of charge, and excitations between surface features including coupling to lattice vibrations. This is certainly an important area for further development. However, simpler approaches, for example, based on calculating singlet-triplet energy differences, can already serve as a semi-quantitative guide.

In summary, we have presented a detailed investigation into the optical properties of Ba-doped $\mathrm{MgO}$ powders and show that these materials possess a number of characteristics which make them attractive for application as luminescent materials. In particular, this material employs nontoxic, highly stable, and widely available substances, is simple to synthesize, and exhibits continuous PL emission in the visible range using only a single dopant. In addition, the fact that quantum yields can be improved by reducing particle size is highly desirable for SSL downconverter applications. While the materials presented here have not been optimized for any individual application, they demonstrate a great deal of potential. More generally, surface-doped ionic materials represent a relatively unexplored new class of PL material which deserves further attention.

Acknowledgements K. P. M. acknowledges support from EPSRC (EP/K003151). This work made use of the facilities of Archer, the UK's national high-performance computing services, via our membership in the UK HPC Materials Chemistry Consortium, which is funded by EPSRC (EP/L000202). A. S. and O. D. acknowledge support from the Deutsche Forschungsgemeinschaft project DI 1613/2-1. The authors acknowledge useful discussions with Peter Sushko and Alex Shluger and are grateful for support by COST Action (CM1104) "Reducible oxide chemistry, structure and functions."

Open Access This article is distributed under the terms of the Creative Commons Attribution 4.0 International License (http://crea tivecommons.org/licenses/by/4.0/), which permits unrestricted use, distribution, and reproduction in any medium, provided you give appropriate credit to the original author(s) and the source, provide a link to the Creative Commons license, and indicate if changes were made.

\section{References}

1. McKittrick J, Shea-Rohwer LE (2014) Review: down conversion materials for solid-state lighting. J Am Ceram Soc 97:1327-1352

2. Han JK, Choi JI, Piquette A, Hannah M, Anc M, Galvez M, Talbot JB, McKittrick J (2012) Phosphor development and integration for near-UV LED solid state lighting. ECS J Solid State Sci Technol 2:R3138-R3147

3. Feinle A, Lavoie-Cardinal F, Akbarzadeh J, Peterlik H, Adlung M, Wickleder C, Hüsing N (2012) Novel sol-gel precursors for thin mesoporous $\mathrm{Eu}(3+)$-doped silica coatings as efficient luminescent materials. Chem Mater 24(19):3674-3683
4. Sandmann A, Kompch A, Mackert V, Liebscher CH, Winterer M (2015) Interaction of L-cysteine with $\mathrm{ZnO}$ : structure surface chemistry, and optical properties. Langmuir. doi:10.1021/ la504968m

5. Feldmann C (2011) Luminescent nanomaterials. Nanoscale 3(5): $1947-1948$

6. Feldmann C, Jüstel T, Ronda CR, Schmidt PJ (2003) Inorganic luminescent materials: 100 years of research and application. Adv Func Mater 13(7):511-516

7. Ragnarsdóttir KV (2008) Rare metals getting rarer. Nat Geosci $1: 720-721$

8. Zhao W, Anghel S, Mancini C, Amans D, Boulon G, Epicier T, Shi Y, Feng XQ, Pan YB, Chani V, Yoshikawa A (2011) $\mathrm{Ce}^{3+}$ dopant segregation in $\mathrm{Y}_{3} \mathrm{Al}_{5} \mathrm{O}_{12}$ optical ceramics. Opt Mater 33(5):684-687

9. Stankic S, Müller M, Diwald O, Sterrer M, Knözinger E, Bernardi J (2005) Size-dependent optical properties of $\mathrm{MgO}$ nanocubes. Angew Chem Int Ed 44(31):4917-4920

10. Stankic S, Bernardi J, Diwald O, Knözinger E (2006) Optical surface properties and morphology of $\mathrm{MgO}$ and $\mathrm{CaO}$ nanocrystals. J Phys Chem B 110(28):13866-13871

11. Sushko PV, Shluger AL, Catlow CRA (2000) Relative energies of surface and defect states: ab initio calculations for the $\mathrm{MgO}$ (001) surface. Surf Sci 450(3):153-170

12. Sushko PV, Gavartin JL, Shluger AL (2002) Electronic properties of structural defects at the $\mathrm{MgO}$ (001) surface. J Phys Chem B 106(9):2269-2276

13. Sternig A, Stankic S, Müller M, Bernardi J, Knözinger E, Diwald O (2008) Photoluminescent nanoparticle surfaces: the potential of alkaline earth oxides for optical applications. Adv Mater 20(24):4840-4844

14. Sternig A, Müller M, McCallum M, Bernardi J, Diwald O (2010) $\mathrm{BaO}$ clusters on $\mathrm{MgO}$ nanocubes: a quantitative analysis of optical-powder properties. Small 6(4):582-588

15. Sushko PV, McKenna KP, Shluger AL, Diwald O (2009) ECS Trans 25:131-139

16. Sushko PV, McKenna KP, Muñoz Ramo D, Shluger AL, Sternig A, Stankic S, Müller M, Diwald O (2010) Photoluminescence properties of alkaline-earth oxide nanoparticles. ECS Trans 28(3):67-80

17. Talapin DV, Rogach AL, Kornowski A, Haase M, Weller H (2001) Highly luminescent monodisperse CdSe and CdSe/ $\mathrm{ZnS}$ nanocrystals synthesized in a hexadecylamine-trioctylphosphine oxide-trioctylphospine mixture. Nano Lett 1(4):207-211

18. Colvin VL, Schlamp MC, Alivisatos AP (1994) Light-emitting diodes made from cadmium selenide nanocrystals and a semiconducting polymer. Nature 370(6488):354-357

19. Empedocles SA, Neuhauser R, Shimizu K, Bawendi MG (1999) Photoluminescence from single semiconductor nanostructures. Adv Mater 11(15):1243-1256

20. van Dijken A, Meulenkamp EA, Vanmaekelbergh D, Meijerink A (2000) The kinetics of the radiative and nonradiative processes in nanocrystalline $\mathrm{ZnO}$ particles upon photoexcitation. J Phys Chem B 104:1715-1723

21. van Dijken A, Meulenkamp EA, Vanmaekelbergh D, Meijerink A (2000) Identification of the transition responsible for the visible emission in $\mathrm{ZnO}$ using quantum size effects. J Lumin 90(3): $123-128$

22. Wang T, Chirmanov V, Chiu WHM, Radovanovic PV (2013) Generating tunable white light by resonance energy transfer in transparent dye-conjugated metal oxide nanocrystals. J Am Chem Soc 135:14520-14523

23. Wang T, Farvid SS, Abulikemu M, Radovanovic PV (2010) Sizetunable phosphorescence in colloidal metastable gamma- $\mathrm{Ga}_{2} \mathrm{O}_{3}$ nanocrystals. J Am Chem Soc 132:9250-9252 
24. Wobbe Milena C C, Kerridge A, Zwijnenburg MA (2014) Optical excitation of $\mathrm{MgO}$ nanoparticles; a computational perspective. Phys Chem Chem Phys 16(40):22052-22061

25. Weigend F, Ahlrichs R (2005) Balanced basis sets of split valence, triple zeta valence and quadruple zeta valence quality for $\mathrm{H}$ to $\mathrm{Rn}$ : design and assessment of accuracy. Phys Chem Chem Phys 7(18):3297-3305

26. Reisfeld R (2002) Fluorescent dyes in sol-gel glasses. J Fluoresc 12(3-4):317-325

27. Sokolov I, Naik S (2008) Novel fluorescent silica nanoparticles: towards ultra bright silica nanoparticles. Small 4(7):934-939

28. Pinto RJB, Carlos LD, Marques PAAP, Silvestre AJD, Freire CSR (2014) An overview of luminescent bio-based composites. J Appl Polym Sci. doi:10.1002/app.41169

29. Layek A, Stanish PC, Chirmanov V, Radovanovic PV (2015) Hybrid $\mathrm{ZnO}$-based nanoconjugate for efficient and sustainable white light generation. Chem Mater 27(3):1021-1030

30. McKenna KP, Koller D, Sternig A, Siedl N, Govind N, Sushko PV, Diwald O (2011) Optical properties of nanocrystal interfaces in compressed $\mathrm{MgO}$ nanopowders. ACS Nano 5(4):3003-3009

31. McKenna KP, Sushko PV, Shluger AL (2007) Inside powders: a theoretical model of interfaces between $\mathrm{MgO}$ nanocrystallites. J Am Chem Soc 129(27):8600-8608

32. Winterer M (2002) Nanocrystalline ceramics: synthesis and structure, springer series in materials science, vol 53. Springer, Berlin

33. Stankic S, Sterrer M, Hofmann P, Bernardi J, Diwald O, Knözinger E (2005) Novel optical surface properties of $\mathrm{Ca}^{2+}$-doped $\mathrm{MgO}$ nanocrystals. Nano Lett 5(10):1889-1893

34. Sternig A, Klacar S, Bernardi J, Stöger-Pollach M, Grönbeck H, Diwald O (2011) Phase separation at the nanoscale: structural properties of $\mathrm{BaO}$ segregates on $\mathrm{MgO}$-based nanoparticles. J Phys Chem C 115(32):15853-15861
35. Stankic S, Sternig A, Finocchi F, Bernardi J, Diwald O (2010) Zinc oxide scaffolds on $\mathrm{MgO}$ nanocubes. Nanotechnology $21: 355603$

36. Lewis GV, Catlow CRA (1985) Potential models for ionic oxides. J Phys C 18(6):1149-1161

37. Giamello E, Paganini MC, Murphy DM, Ferrari AM, Pacchioni G (1997) A combined EPR and quantum chemical approach to the structure of surface $\mathrm{F}_{\mathrm{s}}+(\mathrm{H})$ centers on $\mathrm{MgO}$. J Phys Chem B 101(6):971-982

38. Ricci D, Pacchioni G, Sushko PV, Shluger AL (2002) Electron trapping at neutral divacancy sites on the $\mathrm{MgO}$ surface. J Chem Phys 117(6):2844

39. Chiesa M, Paganini MC, Giamello E, Murphy DM, Di Valentin C, Pacchioni G (2006) Excess electrons stabilized on ionic oxide surfaces. Acc Chem Res 39(11):861-867

40. Becke AD (1993) Density-functional thermochemistry. III. The role of exact exchange. J Chem Phys 98(7):5648-5652

41. Sternig A, Koller D, Siedl N, Diwald O, McKenna K (2012) Exciton formation at solid-solid interfaces: a systematic experimental and ab initio study on compressed $\mathrm{MgO}$ nanopowders. J Phys Chem C 116(18):10103-10112

42. Valiev M, Bylaska EJ, Govind N, Kowalski K, Straatsma TP, van Dam HJJ, Wang D, Nieplocha J, Apra E, Windus TL, de Jong WA (2010) NWChem: a comprehensive and scalable opensource solution for large scale molecular simulations. Comp Phys Commun 181(9):1477-1489

43. Frisch MJ et al (2003) GAUSSIAN 03 revision D02. Gaussian Inc., Wallingford

44. Hofmann P, Knözinger E, Diwald O, Mustafa A (1997) Thermally stable $\mathrm{CaO}$ surfaces on highly dispersed $\mathrm{MgO}$ - new aspects for methane activation. Ber Bunsen Phys Chem 101(11):1722-1725 